\title{
RESERVA ORÇAMENTÁRIA: ESTUDO DE CASO EM UMA EMPRESA COMERCIAL
}

\section{BUDGETARY RESERVE: CASE STUDY IN A RETAIL COMPANY}

\begin{abstract}
RESUMO
Este estudo analisa a percepção dos agentes sobre a criação da reserva orçamentária no processo de planejamento de uma empresa comercial. Para tanto, foi desenvolvido a partir de uma pesquisa empírico descritiva, com uma abordagem interpretativa por meio de um estudo de caso em uma empresa de grande porte. Os resultados denotam que a percepção sobre a criação de reserva orçamentária não contribui com as práticas gerenciais adotadas, pois torna as metas pouco desafiadoras, principalmente em ambiente de retração de vendas e redução de gastos. Constatou-se que a maioria dos agentes negam a existência de reserva orçamentária e afirma que a prática não traz benefício algum à empresa. Nos casos em que os agentes reconhecem a existência da reserva orçamentária, eles enfatizaram que tal prática ocorre de forma não intencional, em decorrência de incerteza nas metas a serem estabelecidas. Assim, conclui-se que todos os agentes possuem conhecimento sobre o que é reserva orçamentária e que a inexistência desta reserva na empresa, na percepção do Controller, influencia os gestores a atingir as metas estabelecidas pela gestão e garantir o controle e o bom funcionamento de todo o sistema orçamentário. Enfatize-se que no caso em que o agente reconheceu o uso da reserva orçamentária, este fato foi motivado pela incerteza das metas estabelecidas, mas ressalte-se que a maioria dos agentes afirmam que essa prática não faz parte do processo orçamentário. Este estudo contribui, tanto no aspecto teórico quanto no prático, com a literatura sobre reserva orçamentária, expandindo os estudos sobre essa temática no país.
\end{abstract}

Palavras-chave: Teoria da Agência; Orçamento; Reservas Orçamentárias.

\begin{abstract}
This study analyzes the agents' perception about the creation of the budget reserve in the planning process of a commercial company. Therefore, it was developed from a descriptive empirical research, with an interpretative approach through a case study in a large company. The results show that the perception about the creation of budget reserve does not contribute to the management practices adopted, as it makes the goals less challenging, especially in an environment of sales retraction and cost reduction. It was found that most agents deny the existence of budgetary reserve and affirms that the practice has no benefit to the company. When the agents recognize the existence of the budget reserve, they emphasized that this practice occurs unintentionally, due to uncertainty in the goals to be established. Thus, it is concluded that all agents have knowledge about what is budget reserve and that the absence of this reserve in the company, according to the Controller, influences managers to achieve the goals set by management and ensure the control and smooth operation of the entire budget system. It is emphasized that in the case where the agent recognized the use of the budget reserve, this fact was motivated due to the uncertainty of the established goals, but it is emphasized that most agents claim that this practice is not part of the budget process. This study contributes, both theoretically and practically, to the budget reserve literature, expanding the studies on this theme in the country.
\end{abstract}

Keywords: Theory of the Agency; Budget; Budgetary Reserves

\section{Thaisa Renata dos Santos}

Mestre em Ciências Contábeis pela Universidade Federal de Goiás (UFG). Especialista em Auditoria e Gestão de Tributos pela Pontifícia Universidade Católica de Goiás (PUC GO). Graduado em Ciências Contábeis pela Pontifícia Universidade Católica de Goiás (PUC GO). Docente do curso de Ciências Contábeis na Pontifícia Universidade Católica de Goiás (PUC G0). Contato: Rua JV 18, Qd.26, Lt.33, Cond. Res. Jd. Venezza, Senador Canedo, Goiás, CEP: 75.254-053. E-mail: thaisarenatax10@gmail.com

\section{Cléber Roberto de Sena Veloso}

Mestre em Ciências Contábeis pela Universidade Federal de Goiás (UFG). Especialista em Docência Universitária pela Faculdade Brasileira de Educação e Cultura (FABEC). Graduado em Ciências pela Universidade Federal de Goiás (UFG). Docente do curso de Ciências Contábeis no Instituto Aphonsiano de Educação Superior. Contato: Rua José Vital Filho, Q-A, Lt 2, Setor Morada do Lago, Trindade, Goiás, CEP: 74.775-004. E-mail: cleberrsena@gmail.com

\section{Ercilio Zanolla}

Doutor em Ciências Contábeis pelo Programa MultiInstitucional e Inter-regional de Pós-graduação em Ciências Contábeis - UnB/UFPB/UFRN. Mestre em Ciências Contábeis pela Universidade do Estado do Rio de Janeiro. Graduação em Ciências Contábeis pela Universidade Federal de Mato Grosso do Sul. Docente do Curso de Ciências Contábeis da Faculdade de Administração, Ciências Contábeis e Ciências Econômicas da Universidade Federal de Goiás - FACE/UFG e do Programa de Pós-graduação em Ciências Contábeis da UFG PPGCONT/UFG. Contato: Rua J 57, Quadra 104 Lote 17, Setor Jaó, Goiânia, Goiás, CEP: 74.674-230 E-mail: zanolla@ufg.br

\section{Júlio Orestes da Silva}

Doutor em Ciências Controladoria e Contabilidade pela Universidade de São Paulo (FEA/USP). Mestre em Ciências Contábeis pela Fundação Universidade Regional de Blumenau (FURB). Graduação em Ciências Contábeis pela Fundação Universidade Regional de Blumenau (FURB). Docente do Curso de Ciências Contábeis da Faculdade de Administração, Ciências Contábeis e Ciências Econômicas da Universidade Federal de Goiás - FACE/UFG e do Programa de Pós-graduação em Ciências Contábeis da UFG - PPGCONT/UFG. Contato: Avenida Esperança s/n, Campus Samambaia, Goiânia, Goiás, CEP: 74690-900. E-mail: orestesj@gmail.com 


\section{INTRODUÇÃO}

O planejamento e o controle adotados nas organizações apresentam como objetivo acompanhar resultados e contribuir para o alcance das metas da entidade (WELSH, 2010). O controle é utilizado como uma ação necessária para verificar se os planos estão sendo devidamente obedecidos, pois é o elo de comunicação dos objetivos da empresa, sustentados nas determinações efetuadas pela empresa por meio do planejamento estratégico (WELSH, 2010).

O controle gerencial é utilizado como um mecanismo para influenciar o comportamento dos membros da empresa, relacionado a artefatos empresariais como, por exemplo, o orçamento empresarial, que pode influenciar o comportamento dos indivíduos na empresa (BRUNS; WATERHOUSE,1975).

Afinal, trata-se de um artefato que não é obrigatório nas organizações e cuja concepção e uso são distintos nas organizações empresariais (FREZATTI; BECK; SILVA, 2013). A função do controle e planejamento associado ao orçamento empresarial está sustentada na Teoria da Agência, que, conforme afirmam Jensen e Meckling (1976), representa a delegação de poderes do principal ao agente, que nesse artigo são os gestores, para alcançar os objetivos pretendidos pela empresa por meio de contratos e visando a diminuição de assimetria informacional. Portanto, uma das atribuições dos agentes é a execução do planejamento e do controle orçamentário, juntamente com diversos artefatos gerenciais, buscando o atingimento de objetivos e metas estratégicas para continuidade do negócio (BEUREN; VERHAGEM, 2015).

Ressalte-se que um dos elementos mais questionados em torno do orçamento formalizado nas organizações é a reserva orçamentária (budgetary slack), analisada pelas empresas em várias perspectivas (FREZATTI; BECK; SILVA, 2013). Assim, a motivação para a criação da reserva, também denominada de folga orçamentária, tem sido objeto de estudo nas últimas décadas e dentre as variáveis abordadas estão a satisfação no trabalho, a motivação, o desempenho, entre outras (SANTOS et al., 2016).

A folga orçamentária também tem sido constantemente objeto de pesquisas em âmbito internacional (CHRISTENSEN; TEMPLIN, 2000). No Brasil, entretanto, os estudos dessa temática surgiram a partir de 1996 (SANTOS et al., 2016) e ainda carecem de estudos direcionados às peculiaridades das organizações e do uso deste artefato no controle organizacional (SANTOS et al., 2016). Alguns estudos investigaram a relação entre a existência da folga orçamentária e a remuneração variável despendida com os gestores, pois quando os gestores são avaliados por meio de metas individuais ou coletivas a criação de folga no orçamento torna-se um mecanismo oportuno (BEUREN; VERHAGEM, 2015).

A criação de folga orçamentária significa a escolha de um padrão de resultados que pode ser facilmente alcançado pelas demais áreas da empresa, e que tende a influenciar a eficácia do sistema orçamentário, pois um sistema de controle gerencial alinhado com os objetivos da empresa, em que as metas são claras e as distorções orçamentárias discutidas, a existência ou não de reserva orçamentária tende a proporcionar mais segurança à gestão no acompanhamento da evolução do negócio (BEUREN; VERHAGEM, 2015). Assim, independentemente do sistema de controle orçamentário utilizado nas organizações, uma questão que se apresenta é: Qual a percepção dos agentes sobre a criação da reserva orçamentária no processo de planejamento de uma empresa comercial? Dessa forma, para buscar responder este problema, adotou-se como objetivo analisar a percepção dos agentes sobre a reserva orçamentária no processo de planejamento orçamentário de uma empresa comercial.

A estratégia de pesquisa utilizada é um estudo de caso mediante entrevistas em uma empresa comercial, no ramo varejista, com sessenta anos de história, e que possui o departamento de controladoria implantado no ano de 2009.

Este estudo contribui, tanto do ponto de vista teórico quanto prático, com a literatura sobre reserva orçamentária, pois possibilita expandir os estudos sobre essa temática no país. O estudo está estruturado em cinco sessões, iniciando com a introdução; em seguida apresenta-se a fundamentação teórica, com destaque à caracterização e às funções da reserva orçamentária, assim como a sustentação teórica por meio da Teoria da Agência. Na sequência, aborda-se o método e os procedimentos de pesquisa; posteriormente são apresentados os resultados e, por último, as considerações finais e a bibliografia da pesquisa.

\section{REFERENCIAL TEÓRICO}

Para responder ao objetivo deste estudo, o referencial teórico está subdividido em três seções: (i) planejamento estratégico e controle gerencial, (ii) orçamento empresarial e (iii) teoria da agência e reserva orçamentária.

\subsection{Planejamento Estratégico e Controle Gerencial}

A literatura sobre controle organizacional afirma que um efetivo planejamento e controle são ações fundamentais para o alcance das metas e objetivos das organizações (FREZATTI et al., 2011). Clássicos da administração definem o termo planejamento como uma das funções primordiais, que significa decidir antecipadamente por uma alternativa de ação em detrimento de outras disponíveis, conforme as preferências, disponibilidades, grau de aceitação do risco, entre outras (FREZATTI, 2009). O Planejamento Estratégico envolve decisões com efeitos de longo prazo e que impactam várias atividades da empresa (ACKOFF, 1976).

Segundo Mintzberg, Ahlstrand e Lampel (2009), a estratégia como um plano depende do planejamento esperado, ou seja, o que as organizações desejam fazer. Esses autores defendem que a estratégia possui duas finalidades: uma como 
ferramenta prospectiva; outra como verificação de padrão de situações passadas - o que efetivamente a empresa fez no decorrer do tempo.

Já o termo controle tem sido utilizado de maneira enfática, pois na verdade o que se pretende no universo empresarial é garantir que todas as decisões tomadas realmente ocorram (FREZATTI, 2009). Dessa forma, pode-se entender que tanto o planejamento estratégico quanto o controle gerencial são premissas fundamentais para uma gestão eficiente, que se relaciona a artefatos gerenciais, como o orçamento, para atingir as metas e objetivos organizacionais (WELSH, 2010).

Neste contexto, as estratégias são valorizadas e o conjunto de artefatos, rotinas e procedimentos, aqui denominados de estrutura, é desenvolvido na empresa. O conjunto de artefatos pode ser variado e busca atender às funções relevantes do modelo de gestão da empresa, no entanto os mais citados são: o planejamento estratégico, BSC -Balanced Scorecard e o controle orçamentário (FREZATTI, 2009).

\subsection{Orçamento empresarial}

O orçamento é o plano financeiro para implementar a estratégia da empresa para um dado exercício (FREZATTI et al., 2010) e pode ser implementado para consecução de muitos objetivos, incluindo planejamento, controle e organização de atividades (COVALESKI et al., 2006). Alguns autores já definiram os motivos que levaram algumas organizações a implementarem o orçamento. Hansen e Van Der Stede (2004) destacam os seguintes motivos: plano operacional, elemento para avaliação de desempenho, instrumento para comunicação de objetivos e formação de estratégias.

Cabe ressaltar que as empresas podem embasar as metas do orçamento por meio de base histórica, base zero ou base mista (WELSH, 2010). O orçamento de base histórica é elaborado para o exercício desejado, levando-se em consideração os números do ano anterior (WELSH, 2010). Em contrapartida, o orçamento base zero não utiliza dados históricos das receitas e despesas da organização para que seja efetuada uma análise de toda despesa futura e receita presente, o que tende a permitir um novo cenário de acordo com a realidade atual, evitando que erros passados perpetuem (COSTA; DE OLIVEIRA MORITZ; MACHADO, 2017). Assim, o orçamento com base mista contempla metas a partir de dados históricos, como também a aplicação e base zero para determinadas metas (WELSH, 2010). A escolha de qualquer um dos métodos exige do gestor a organização de plano orçamentário a partir de decisões que facilitem o processo de tomada de decisões objetivando as estratégias da empesa (COSTA; DE OLIVEIRA MORITZ; MACHADO, 2007).

Assim, o orçamento empresarial é considerado o principal artefato no sistema gerencial, permitindo determinar a estimativa de lucro e também o acompanhamento do desempenho econômico, comparando com o valor orçado (ANTHONY; GOVINDARAJAN, 1998). Além disso, o orçamento é um instrumento com muitas nuances e potenciais conflitos no tempo, na hierarquia e mesmo no direcionamento, pois, ao mesmo tempo que direciona a empresa para o futuro, contemplando as estratégias, exige a definição de metas que serão utilizadas para avaliar desempenho de áreas e pessoas (FREZATTI; BECK; SILVA, 2013). As tensões e interesses por trás do orçamento não podem ser ignorados para que o instrumento seja utilizado minimizando conflitos internos nas organizações, visto ser natural que as pessoas, quando operacionalizam uma estratégia em uma meta, face às incertezas do ambiente, optem por uma meta que não as desfavoreçam (FREZATTI; BECK; SILVA, 2013).

Já que a construção do orçamento é conjunta e uma das perspectivas é dispor de um artefato que persiga o aumento da eficiência, ter reservas pode significar a perda da informação que representa a otimização de resultados, pois, em um ambiente participativo de planejamento as metas contemplam desafios exequíveis e assim a relação entre as pessoas torna-se importante. Em contrapartida, identificar o que é uma reserva não é uma tarefa fácil quando se vive em um ambiente de mudança e incerteza (FREZATTI; BECK; SILVA, 2013).

\subsection{Teoria da Agência e Reserva Orçamentária}

Uma relação de agência é definida como um contrato que rege a contratação de uma pessoa (agente) para executar em nome do contratante (principal) um serviço que resulte na delegação de algum poder de decisão (JENSEN; MECKLING, 1976). Se as partes forem maximizar sua utilidade, existem razões para crer que nem sempre as ações do agente estarão alinhadas com os interesses do principal (JENSEN; MECKLING, 1976). Este, por sua vez, pode restringir tal comportamento através da concessão de incentivos adequados para o agente e despender custos de monitoramento com objetivo de reduzir as atividades irregulares do agente (JENSEN; MECKLING, 1976). Tais custos são classificados como (1) despesas de monitoramento, (2) despesas com compromissos contratuais e (3) custo residual. Assim, os custos de agência aparecem em qualquer contexto em que haja cooperação entre duas ou mais pessoas, ainda que não exista, de forma bem definida, a relação principal-agente (JENSEN; MECKLING, 1976).

Duan (2014) afirma que devido ao interesse inconsistente entre o superior e os subordinados, nos casos em que a avaliação de desempenho é empregada tendo orçamento como base, os subordinados podem maximizar os seus interesses através de comportamentos oportunistas. Segundo Merchant (1985), quando o objetivo de uma empresa é alcançado, parte dos recursos são canalizados para satisfazer indivíduos e, nesse aspecto, a reserva orçamentária e a Teoria da Agência são semelhantes. Duan (2014) corrobora este entendimento ao afirmar que pesquisas sobre a folga orçamentária estão intimamente associadas com a Teoria da Agência e são um ramo importante da economia moderna. 
Para Merchant (1985) a reserva orçamentária corresponde ao valor orçado em uma área da empresa acima do necessário. Young (1985) define folga orçamentária como a situação em que subordinados alocam, intencionalmente, excesso de recursos no orçamento ou, conscientemente, subestimam a capacidade de produção.

Cabe ressaltar a dificuldade de reunir pesquisas na literatura sobre reserva orçamentária em razão das múltiplas formas como são citadas e também pelos diversos conceitos abordados (MERCHANT, 1985). Na literatura sobre comportamento organizacional e comportamento de gestores, pode-se encontrar o assunto referenciado como "normas orçamentárias frouxas", "falta de congruência de metas", "polarização gerencial”, "respostas táticas defensivas" e "comportamentos enganosos" (SANTOS et al., 2016). Santos et al. (2016) demonstram que esse contexto ainda não foi totalmente modificado, pois estudos sobre reserva orçamentária são crescentes, possivelmente pela falta de consolidação do assunto na literatura.

Duan (2014) associa a reserva orçamentária a diversas teorias, entre elas a Teoria da Agência, Teoria Comportamental, Teoria Psicológica e Teoria da Motivação. Além disso, Santos et al. (2016) evidenciam que a reserva orçamentária tem sido investigada conjuntamente com diversas variáveis organizacionais, tais como a participação no orçamento, a assimetria da informação e a ênfase orçamentária. Ressalte-se também que a constituição de reserva orçamentária vem sendo estudada sob aspectos comportamentais e psicológicos, com variáveis tais como honestidade dos gestores, percepção de justiça organizacional, valores, reputação e inclusive relacionada à ética (SANTOS et al., 2016).

Merchant (1985) afirma que a propensão para criar folga orçamentária parece ocorrer em todas as empresas. Dunk (1990) evidencia que o orçamento participativo não necessariamente elimina o conflito de interesse e, por isso, os superiores podem precisar de cautela, pois enquanto eles podem usar a participação para ampliar o acesso a informações privilegiadas, os subordinados podem manipular o processo para obter orçamentos operacionais mais fáceis. Duan (2014) complementa, argumentando que, quando o orçamento é tomado como base para a avaliação de desempenho, os gerentes se inclinam a formular folga orçamentária para obter lucro residual e assegurar a sua remuneração. Ainda assim, Duan (2014) afirma que, como uma espécie de modelo de gestão, o orçamento é uma base essencial e ser contratada para avaliar o desempenho do gestor.

Huang e Chen (2009) afirmam que enquanto os gestores se dedicam para alcançar seus orçamentos tendem a proteger a precisão e o bom funcionamento do sistema orçamental, logo teriam atitudes positivas para minimizar a reserva orçamentária. Os estudos de Huang e Chen (2009) sugerem que a educação pode ser uma boa maneira de estimular atitudes mais positivas com relação ao orçamento e consequente redução da folga orçamentária. Segundo estes autores os superiores devem solicitar orçamentos atingíveis e, antes de decidir como alocar os recursos, comunicar de forma clara a proposta do orçamento. Desse modo, os gestores são impedidos de usar táticas tortuosas para inserir folga real em seus orçamentos.

Além disso, a Teoria da Agência clássica aparece como ponto de partida adequado para a construção do problema da criação de reserva orçamentária. Não é capaz, no entanto, de explicar totalmente o fenômeno devido às suposições restritivas, especialmente em relação à função de utilidade dos indivíduos, que só consideram a riqueza e negligenciam outras preferências, o que sugere aspectos comportamentais e psicológicos para justificar o aumento na folga orçamentária (LIESSEM et al., 2015). Segundo Liessem et al. (2015) as preferências sociais e a teoria da justiça organizacional mostram que os indivíduos não são interessados apenas em maximizar a riqueza pessoal e minimizar o esforço, mas em adquirir eficiência profissional. Nesse aspecto, preferências por honestidade e justiça dificultam a criação de reserva orçamentária, embora sejam incapazes de evitar completamente esse problema.

De acordo com Duan (2014) existem pontos de vista negativos e positivos sobre a criação de reserva orçamentária. Segundo o autor a reserva orçamentária levará à distribuição inadequada de recursos escassos, à avaliação inadequada dos gestores e, portanto, ao aumento dos custos de agência entre o superior e os subordinados, além de provocar a redução na eficiência operacional da empresa. Em contrapartida, Duan (2014) afirma que, em algumas condições, a folga orçamentária tem efeitos positivos, especialmente em ambiente incerto, que pode reduzir a incerteza e manter o desenvolvimento estável para enfrentar os riscos do mercado. Ademais, quando as empresas enfrentam diferentes estratégias de desenvolvimento, a adequada folga orçamental também pode satisfazer as exigências da estratégia de desenvolvimento da empresa (DUAN, 2014). Portanto, a combinação equilibrada entre os fatores negativos e positivos é a chave para lidar com a reserva orçamentária, pois, uma vez que a relação de agência, a assimetria informacional e os erros de orçamento são inevitáveis, a folga orçamentária adequada tende a ser benéfica para a companhia, inclusive em explorar novas ideias na empresa, além de suportar custos de desenvolvimento e implementação de inovações (DUAN, 2014; BEUREN; VERHAGEM, 2015).

\section{MÉTODOS E TÉCNICAS DA PESQUISA}

A estratégia de pesquisa envolve os meios técnicos da investigação e corresponde ao planejamento e estruturação da pesquisa (MARTINS; THEÓPHILO, 2016). Neste estudo, a estratégia de pesquisa que será utilizada é o estudo de caso, que, de acordo com Martins e Theóphilo (2016), caracteriza-se pela investigação qualitativa e empírica sobre fenômenos dentro de um contexto social, buscando apreender determinada situação e descrever, compreender e interpretar um caso real.

A técnica de coleta dos dados utilizada nesta pesquisa é a entrevista, uma técnica que coleta informações, dados e evidências cujo objetivo básico é entender e compreender o significado que entrevistados atribuem a questões e situa- 
ções (MARTINS; THEÓPHILO, 2016). O roteiro de entrevista foi desenvolvido sobre a espinha dorsal do orçamento, e buscou-se capturar, por meio de perguntas abertas, informações que permitissem entender o modelo de gestão organizacional e o papel do orçamento da empresa. Para isso, foram desenvolvidos dois roteiros, um voltado para o Controller, como agente principal, e outro para os cargos de gerência das áreas de Recursos Humanos (RH), Compras e Financeira.

A abordagem de avaliação utilizada neste estudo foi uma abordagem qualitativa. A pesquisa qualitativa é utilizada para estudar um fenômeno relativo às ciências humanas e sociais e caracterizado por predominância na descrição de pessoas, situações, acontecimentos, reações, inclusive transcrições e relatos (MARTINS; THEÓPHILO 2016).

Segundo Martins e Theóphilo (2016) uma das técnicas de aferição de confiabilidade é a técnica do Pré-Teste, em que o instrumento de medidas é aplicado previamente para um grupo de pessoas, para produzir um instrumento confiável. Para preservar a validade do roteiro de entrevista, um docente da área contábil avaliou o conteúdo do questionário, a estrutura das perguntas e realizou modificações pertinentes. Em seguida, houve outra aplicação prévia do roteiro de entrevista a um docente do curso de Ciências Contábeis que já atuou profissionalmente em um departamento de controladoria de uma empresa comercial, como uma forma de validação de confiabilidade antes da sua efetiva aplicação.

\section{1 - Constructo do Questionário}

A temática abordada neste estudo busca a evolução das pesquisas na literatura contábil. Assim, a reserva orçamentária e os fatores que motivam sua criação tornam-se o ponto central deste estudo. Neste sentido, as perguntas foram desenvolvidas com base em Frezatti, Beck e Silva (2013), abordando quatro elementos sustentados pela literatura sobre reservas orçamentárias, conforme evidenciado na Figura 1.

Figura 1 - Constructo do questionário

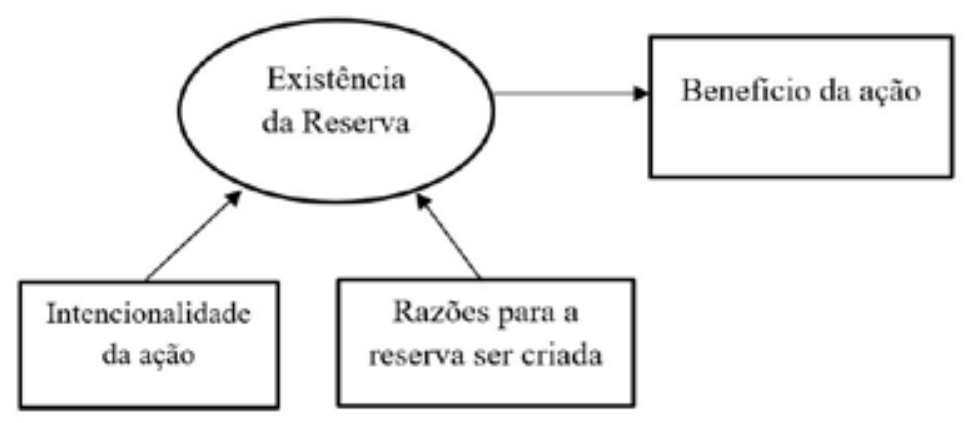

Fonte: Elaborado a partir de Frezatti, Beck e Silva (2013).

Percebe-se por meio da Figura 1 que o primeiro elemento a ser investigado se refere à existência da reserva. Ou seja, subestimar ou superestimar um alvo deve estar orientado em propósitos referenciais (HOBSON; MELLON; STEVENS, 2011). Portanto, investigar se o entrevistado acredita que a existência de reservas é importante é a premissa para identificar qual o motivo para a criação da reserva, se a criação é intencional ou não e, por fim, os impactos da ação.

Assim, o segundo elemento a ser investigado refere-se à intencionalidade da ação. Ou seja, trata-se de um elemento subjetivo (DUNK; NOURI, 1998), mas que pode revelar se os gestores, intencionalmente ou não, criaram reservas. Se houver na política de remuneração dos executivos um vínculo ao alcance de metas, a intencionalidade torna-se evidente (BEUREN; VERHAGEM, 2015).

O terceiro elemento do constructo aborda as razões para a reserva ser criada. Este elemento pode evidenciar diversos motivos, como as características da estrutura organizacional e o controle orçamentário (BRUNS; WATERHOUSE, 1975) e a assimetria informacional, caracterizada como um fator relevante para a criação das reservas (YUEN, 2004).

O último elemento refere-se ao benefício da ação de criação da reserva orçamentária. Este elemento está relacionado principalmente a investigar se o benefício da reserva está vinculado à remuneração de algum gestor (LEAVINS; OMER; VILUTIS, 1995).

Dessa forma, o roteiro de entrevista foi estruturado em seis blocos e composto pelo total de 25 perguntas. O primeiro bloco busca abordar a visão dos gestores em relação ao planejamento e ao controle orçamentário, abrangendo a importância desses processos na empresa e contemplou treze perguntas. O segundo bloco é inerente à existência da reserva orçamentária e contempla duas perguntas. O terceiro bloco, que contempla duas perguntas, refere-se à identificação da intencionalidade dos entrevistados para criação da reserva orçamentária na empresa. O quarto bloco verifica, por meio de uma pergunta, os motivos e razões para a criação da reserva. O quinto bloco objetiva verificar o benefício da ação para criação da reserva orçamentária e contemplou uma pergunta. Ressalte-se que do segundo ao quinto bloco encontram-se as perguntas que sustentam o tema central deste trabalho, e buscam verificar a concepção dos gestores com relação aos quatro elementos do constructo desta pesquisa. O sexto e último bloco teve o intuito de identificar algumas características dos participantes, com o objetivo de traçar o perfil dos respondentes por meio de seis perguntas. 
As entrevistas foram realizadas individualmente em uma das salas de reunião da empresa com prévio agendamento. Durante o processo de entrevistas, os discursos foram devidamente gravados e transcritos, mediante autorização prévia. Ressalta-se que o prazo médio de entrevistas foi de quarenta minutos para cada participante.

\section{2 - Descrição da Empresa}

A empresa possui 60 anos de história, atua no segmento do varejo e no setor de móveis e eletrodomésticos. Apresenta um quadro de aproximadamente 3.700 funcionários, distribuídos em 200 unidades em nove Estados mais o Distrito Federal. Sob o aspecto de estrutura de propriedade e controle, a empresa corresponde a uma sociedade anônima de capital fechado, cujo controle pertence à família fundadora do negócio, que atualmente possui a gestão familiar concentrada em sua segunda geração. A seleção dessa empresa para investigação do fenômeno de criação de reservas orçamentárias pontua-se na maturidade da empresa, em específico pela utilização do orçamento. Destaque-se também que o departamento de controladoria, responsável pelo acompanhamento do orçamento, é recente: foi implantado na empresa no ano de 2009.

\section{RESULTADOS}

Inicialmente analisou-se o comportamento e a percepção do Controller e das gerências de Recursos Humanos, Financeira e de Compras quanto a utilização do planejamento e do controle orçamentário, pontuando alguns temas que fazem parte deste processo: (i) planejamento; (ii) indicadores de desempenho; (iii) sistemas de informação; (iv) grau de participação no orçamento; (v) grau de força do passado; (vi) cultura de planejamento; (vii) comunicação e (viii) controle orçamentário, conforme o Quadro 1.

Quadro 1 - Percepção dos respondentes sobre Aspectos do Planejamento Orçamentário

\begin{tabular}{|c|c|}
\hline Temas & Resultados \\
\hline Planejamento & $\begin{array}{l}\text { Todos os participantes afirmam que, embora haja dificuldades em projetar cenários, a empresa utiliza } \\
\text { planejamento estratégico e orçamento devidamente formalizado e alinhado com as metas e objetivos da } \\
\text { empresa: "Nós temos o orçamento que é feito anualmente e depois a gente tem as revisões de orçamento" } \\
\text { (Gerente de RH), e que os papéis dos gerentes neste processo envolvem apenas a participação na elabo- } \\
\text { ração do orçamento. Ou seja, apenas as diretorias da empresa e o conselho participam de forma ativa no } \\
\text { planejamento estratégico da empresa: "Os gestores não estão tão envolvidos (com a estratégia), e sim a } \\
\text { alta gestão: diretoria e conselhos" (Controller). }\end{array}$ \\
\hline $\begin{array}{l}\text { Indicadores de } \\
\text { Desempenho }\end{array}$ & $\begin{array}{l}\text { Todos os participantes enfatizaram que a empresa utiliza indicadores estratégicos e financeiros relacio- } \\
\text { nados ao planejamento orçamentário como um mecanismo de mensuração e adequação dos resultados } \\
\text { pretendidos e que tais indicadores podem variar conforme as diversas áreas da empresa: "Sim, a gente } \\
\text { tem até o nosso fluxo de caixa, a gente tem uma forma específica de demonstrar" (Gerente Financeiro). }\end{array}$ \\
\hline Sistemas de Informação & $\begin{array}{l}\text { Em unanimidade, os participantes afirmam que, mesmo com o departamento de controle implantado } \\
\text { recentemente, as informações demandadas pelas áreas envolvidas para fins de planejamento e orçamento } \\
\text { atendem à demanda da empresa e encontram-se constantemente em processo de melhorias: "Temos, } \\
\text { mas a gente ainda precisa melhorar" (Gerente RH). Ou seja, o sistema de informações, que envolve o } \\
\text { planejamento e o orçamento, consegue atingir seu objetivo, mas encontra-se em constante mudança para } \\
\text { melhorias, visando a eficiência do processo. }\end{array}$ \\
\hline $\begin{array}{l}\text { Grau de Participação no } \\
\text { Orçamento }\end{array}$ & $\begin{array}{l}\text { Ressalte-se que todos os participantes afirmaram que os gerentes que participam da elaboração do orça- } \\
\text { mento recebem feedback mensalmente, denotando que o feedback e o grau de participação sobre o de- } \\
\text { sempenho ocorrem normalmente, com regularidade e objetividade: "O feedback é mensal, é efetuado pelo } \\
\text { Controller, o qual afirma que existem gestores de contas com os quais são feitas reuniões todos os meses } \\
\text { para ver se atingiu ou não as metas orçamentárias". }\end{array}$ \\
\hline $\begin{array}{l}\text { Grau de Força do } \\
\text { passado }\end{array}$ & $\begin{array}{l}\text { Quando questionados sobre se as projeções são elaboradas a partir de dados históricos, ou seja, o grau de } \\
\text { influência do passado na elaboração do orçamento, os participantes afirmaram: Controller. "Hoje estamos } \\
\text { trabalhando quase que com base zero [...]. O cenário não permite mais ter uma análise histórica". Gerente } \\
\text { Financeiro: "Não só em dados históricos, uma parte em dados históricos e a outra parte nós temos outras } \\
\text { variáveis". Gerente Recursos Humanos: "Basicamente históricos, [...] então, às vezes tem alguma coisa } \\
\text { futura a considerar". Gerente Compras: "Sim, dados históricos e sazonalidade". Percebe-se que, enquanto } \\
\text { o Controller afirma que quase não existe influência do passado para estimação do orçamento, pois a base } \\
\text { considerada é base zero, o Gerente Financeiro e o de Compras adotam base mista, ou seja, base zero e } \\
\text { também dados históricos. }\end{array}$ \\
\hline
\end{tabular}




\begin{tabular}{|l|l} 
Temas & Resultados \\
Ao serem questionados se a preocupação com as questões de planejamento e orçamento fazem parte da \\
rotina diária, como um processo predominante na cultura da empresa, os participantes afirmaram: Con- \\
troller: "Não, não vejo que hoje [...] a gente vê muitos aspectos para melhorar ainda". Gerente Financeiro: \\
"Sim, tem um impacto direto". Gerente Recursos Humanos: "Sim, isso hoje para a gente é parte do nosso \\
dia a dia". Gerente de Compras: "Faz. Diariamente temos que acompanhar, ir tirando relatórios, fazendo \\
Planejamento \\
acompanhamentos para ver em que pé está. Ver se a gente tem condições de atingir [a meta], se está \\
distante [...]". Assim, quanto ao planejamento e o orçamento fazerem parte da rotina diária, constatou-se \\
que o Controller ainda não considera como um processo em plena eficiência. Entretanto, os gerentes de \\
Recursos Humanos, Financeiro e de Compras acreditam que estão sendo eficientes quanto à qualidade \\
e informações fornecidas, corroborando para a existência de uma cultura de planejamento e orçamento \\
predominante na empresa.
\end{tabular}

Fonte: Elaborado pelos autores.

Os discursos dos agentes entrevistados foram na sua maioria alinhados quanto à prática do planejamento e do controle orçamentário dentro da empresa: os conflitos surgiram nas abordagens dos níveis de (i) grau do passado; (ii) cultura do planejamento e (iii) comunicação.

Nota-se assimetria entre o Controller e os Gerentes Financeiro e de Compras com relação ao grau do passado: enquanto o Controller utiliza base zero, os dois gerentes afirmam utilizar dados históricos no planejamento orçamentário. Esse achado vai ao encontro de Welsh (2010), ao afirmar que para subestimar receitas ou superestimar gastos, a empresa deve se basear em alguma referência e, se esta base se fixar no passado, a empresa desconsidera a definição do planejamento estratégico (WELSH, 2010).

Além disso, o conflito evidenciado com relação a cultura do planejamento e também a comunicação da gestão denota uma assimetria informacional entre os gerentes e o Controller. Segundo Mucci, Frezattti e Dieng (2016) as funções de comunicação entre envolvidos no orçamento possuem relevância superior ao construto de planejamento, o que indica que, apesar de as funções de planejamento serem consideradas mais importantes para cada área da empresa, elas dependem da comunicação para que a utilidade do planejamento orçamentário seja assumida por todas as áreas da empresa.

Foram analisados também o comportamento e a percepção do Controller e das gerências de Recursos Humanos, Financeira e de Compras da empresa quanto à: (i) a existência da reserva; (ii) intencionalidade da ação; (iii) razão para a reserva ser criada e (iv) benefício da ação, conforme o construto deste estudo.

\section{1 - Existência da Reserva}

Quanto à existência da reserva orçamentária o Controller é categórico em afirmar que na empresa não há espaço para nenhum tipo de folga orçamentária, principalmente pelo momento do setor varejista, que é fortemente afetado pela crise econômica que o país enfrenta nos últimos anos: "Na verdade, hoje o cenário não está permitindo nenhum tipo de reserva ou sobra, a gente está muito realista, e eu digo que temos momentos até arrojados porque as metas ficaram desafiadoras". Neste ponto há alinhamento de interesses com os gerentes de recursos humanos e gerente financeiro, pois eles também dizem que não há folga no orçamento. Entretanto, há caso em que a reserva orçamentária é aplicada para facilitar o alcance de metas, configurando-se assim, conflito de interesses.

Neste sentido, a justificativa para a existência de reserva orçamentária advém do gerente de compras, quando afirma que a existência da reserva é para suprir incertezas quanto ao real acontecimento de algum fenômeno: "Necessidade do momento, estratégia adotada e, se persistirem os conflitos, a gente acaba fazendo"; além de garantir o pagamento de comissões variáveis dos vendedores. Além disso, o gerente possui conhecimento do que representa a reserva orçamentária. Gerente de Compras: "Subestimar receitas é planejar-se para receber menores recursos. Superestimar gastos é planejar para gastar mais". 
Ressalte-se que o gerente de compras assumiu essa função recentemente e que esse resultado se justifica nos achados de Beuren e Verhagem (2015), os quais afirmam por meio dos seus estudos que os gestores que possuem desempenho incipiente tendem a criar folgas em seus orçamentos.

O gerente de Recursos Humanos, o Gerente Financeiro e o Controller, que apresentam o discurso de que não reconhecem a existência da reserva, tem essa crença fortemente ligada à atual crise econômica que afeta o setor. Identifica-se, no entanto, que a aplicação da reserva existe como um mecanismo para o alcance de metas, o que caracteriza um conflito de interesses entre os agentes, como se verifica nas respostas transcritas a seguir.

Controller. "Na verdade, hoje o cenário não está permitindo nenhum tipo de reserva ou sobra, a gente está muito realista e eu digo que temos momentos até arrojados porque as metas ficaram desafiadoras [...]”.

Esse resultado denota que a negação da existência da reserva decorre de uma lógica de legitimação da estrutura que valida as metas propostas para a gestão (FREZATTI; BECK; SILVA, 2013).

Nota-se que não existe na empresa nenhum tipo de incentivo para o atingimento das metas, o que é justificado pelo que o Controller considera para avaliar como as metas estão sendo cumpridas. Mais uma vez a preocupação com a crise financeira é evidente, o que pode ser percebido na resposta do Controller, a seguir:

"Consideramos o momento da empresa, porque a empresa vem de queda de vendas nos últimos dois anos, o mercado caiu vertiginosamente nos últimos dois anos e o setor de móveis e eletros foi um dos mais prejudicados na crise, então vamos analisar sempre o mínimo para trabalhar com aquele tipo de empresa, então, as áreas estão bem enxutas, todos os custos estão bem enxutos, porque não tem outra opção, na verdade o fato é esse, se a gente não adequar nossa realidade à realidade do mercado fatalmente a gente vai sair dele".

Segundo Beuren e Verhagem (2015) a existência da reserva nas empresas está relacionada com o fato de a empresa atribuir incentivos relacionados às metas de cada gestão no planejamento orçamentário. Neste sentido, como não há incentivos na empresa, a tendência é de inexistência de reserva. Além disso, o presente estudo vai ao encontro da pesquisa de Huang e Chen (2009), pois afirmaram que quando gestores trabalham duro para alcançar seus orçamentos tendem a proteger a precisão do orçamento e o bom funcionamento do sistema orçamental. Esses gerentes teriam, portanto, atitudes menos positivas com relação à reserva orçamentária.

\section{2 - Intencionalidade da Ação}

Quanto à intencionalidade da ação em subestimar receitas, segundo Controller, neste momento não é uma possibilidade. Embora haja este entendimento por parte do Controller, o gerente de compras reconhece a necessidade de subestimar receitas e superestimar gastos em alguma situação. Em contrapartida, as respostas do gerente financeiro e do gerente de recursos humanos não permitem inferir a existência da reserva orçamentária.

Controller. "A gente não tem esse tipo de situação, creio. Como que a gente sabe e como isso é identificado? Mensalmente a gente faz reunião de apuração de resultado, portanto, assim, a pessoa orçou um milhão e gastou oitocentos mil, no mês que vem só vou dar oitocentos mil".

Gerente Financeiro: "Subestimar receita, geralmente subestima-se receitas que não são assim tão factíveis, pode ser que ela não aconteça naquele determinado mês, então a gente é até um pouco conservador neste ponto... A gente subestima ela. E no caso da superestimação, acontece às vezes de termos [...] alguma despesa que a gente está projetando que vai acontecer e lá, no momento, ela não se realiza [...]”.

Gerente Recursos Humanos: "Se aplica muito forte para a gente (...)".

Gerente de Compras: “(...) Em princípio isso é um conservadorismo. Pensar em uma situação pior para que se possa atingir o ideal, e claro que a gente acaba fazendo isso principalmente no que tange às despesas, para que não estoure”.

Esses resultados denotam que a intencionalidade da ação de criação da reserva orçamentária é muito subjetiva (YOUNG, 1985).

\section{3. - Razões para Reserva ser criada}

A maioria das respostas não permite inferir motivos pelos quais as reservas são criadas, salvo em um caso em que a reserva tem função de conservadorismo, isso é, facilitar o alcance dos objetivos.

Gerente de Compras: "[...] Em princípio isso é um conservadorismo. Pensar em uma situação pior para que se possa atingir o ideal, e claro que a gente acaba fazendo isso principalmente no que tange as despesas, para que não estoure”. A razão para a criação da reserva baseia-se na justificativa de obter uma margem segura no planejamento estratégico da empresa e também garantir um cenário favorável para o setor de compras (Gerente de Compras). Assim, as razões que levam uma empresa para a criação de reservas podem ser diversas e dentre as opções pode ser destacada a exigência da alta administração para atingir um crescimento de lucro através do orçamento (ONSI, 1973).

\section{4 - Benefício da Ação}

Com relação ao benefício da ação, segundo a alta administração, a criação de reserva orçamentária é uma percepção negativa, ou seja, sem muitos benefícios para a atual realidade da empresa. Entre os gerentes há divergências quanto 
aos benefícios, alguns possuem a opinião de que não existe nenhuma vantagem em subestimação de receitas ou superestimação de gastos. A reserva seria um mecanismo para não existir desafio em cumprimento das metas pelas áreas da empresa. Ou seja, a folga orçamentária levaria a um não comprometimento em atingir os objetivos. Há ainda, quem vê o benefício de facilitar o alcance das metas.

Controller. "Então assim, eu não vejo com bons olhos, assim, a não ser que aconteça uma situação bem específica, [...], até porque a meta não fica arrojada, não fica desafiadora, [.... Não vejo como a melhor prática.”.

Gerente Financeiro: "Neste momento, não é possível ter uma reserva orçamentária [...]"

Gerente Recursos Humanos: "No nosso caso não tem benefício, [...]”.

Gerente de Compras: "Bom, conforme foi falado, é conservadorismo na busca de atingir os resultados positivos esperados".

Nos discursos, os benefícios da constituição de reserva orçamentária não são explorados como um mecanismo de alinhamento de interesses e isso pode ser percebido porque a empresa não utiliza remuneração variável individual vinculada ao orçamento empresarial. Ou seja, em uma análise conservadora fundamentada na Teoria da Agência, a reserva orçamentária pode ser constituída por decisão consciente de forma a desejar um maior benefício no contexto de avaliação da empresa.

O Controller e a maioria dos gerentes foram uniformes na afirmação de que não há benefícios na ação para a criação de reserva orçamentária. Controller. "até porque a meta não fica arrojada, não fica desafiadora, se eu considerei cento e vinte eu vou orçar cem, pra quê?”. Este resultado corrobora os achados de Dillon, Paté-Cornell e D. Guikema (2005), os quais afirmam que a criação de reserva é um fator inviável em um ambiente com planejamentos estratégicos em fase de desenvolvimento, pois este cenário é caracterizado por incertezas e complexidades.

O Gerente de Compras, no entanto, afirma que o benefício de criação de reserva orçamentária é claramente evidenciado para facilitar o atingimento de metas: "Bom, conforme foi falado, é conservadorismo na busca de atingir os resultados positivos esperados”. Esse resultado indica a existência de um leque variado de motivações para o desenvolvimento de reserva, profundamente relacionado às configurações e arranjos organizacionais (FREZATTI; BECK; SILVA, 2013).

\section{CONSIDERAÇÕES FINAIS}

O objetivo deste estudo foi verificar a percepção dos agentes em uma empresa comercial sobre a reserva orçamentária no processo de planejamento orçamentário. As pesquisas internacionais afirmam que quando existe um alinhamento e envolvimento participativo de todas as áreas da empresa no processo orçamentário, inclusive com empenho no alcance as metas estabelecidas e o monitoramento da gestão, existe menos probabilidade para a existência de folga orçamentária (HUANG; CHEN, 2009). Em âmbito nacional as pesquisas também indicam que a inexistência da reserva está associada com a forma da estrutura do processo orçamentário, contemplando um sistema de informações relacionado/vinculado com as metas estabelecidas nas estratégicas e o envolvimento da presidência no processo (FREZATTI; BECK, SILVA, 2013).

Em decorrência da análise dos resultados, verificou-se que tanto o planejamento quanto o controle orçamentário são processos formalizados, coerentes com as metas e objetivos da empresa, e em sincronia nas rotinas diárias. Para a elaboração do planejamento utilizam-se indicadores estratégicos para mensurar e adequar os resultados pretendidos. Quanto às atividades de controle orçamentário, existem processos que vão desde o repasse de informações pela controladoria sobre as metas alcançadas para cada gestor até à disponibilização de mecanismos para acompanhamento dos resultados orçados versus realizados. Ressalte-se que as atividades de monitoramento e repasse das informações orçamentárias para a presidência é executada pelo departamento de controladoria, implantado há dez anos (2009) na empresa.

Além disso, na percepção do Controller, a criação de reserva orçamentária não é uma prática aceitável, pois torna as metas pouco desafiadoras, principalmente em ambiente de retração de vendas e redução de gastos como o vivenciado pela empresa no momento. Em contrapartida, os resultados apontam que os gerentes de Recursos Humanos e Financeiro negam a existência de reserva orçamentária no processo de planejamento orçamentário, e afirmam que a prática não traz benefício algum. Ressalte-se que o gerente de compras admite superestimar gastos ou subestimar receitas, devido à não facticidade de algumas receitas e também por conservadorismo. Assim, conforme a análise do conteúdo das entrevistas, infere-se que a negação de existência de reserva decorre do ambiente de monitoramento do orçamento e de uma lógica de legitimação da ação em benefício do cumprimento das metas, de modo que não são vistos como reserva, mas como recursos necessários. Como a subestimação de receitas e superestimação de despesas ocorre no setor de compras da empresa sem o consentimento e aprovação do Controller, denota existência de assimetria informacional. Este achado corrobora outros estudos, segundo os quais a existência de assimetria informacional possibilita a criação de folga orçamentária (SANTOS et al., 2016).

As limitações deste estudo se concentram principalmente na não aplicação do roteiro de entrevista para todas as áreas/níveis de departamentos operacionais, que também participam do processo orçamentário da empresa. Além disso, outra limitação se concentra na inexistência de aplicação desta entrevista ao nível superior da empresa, como, por exemplo, às diretorias e à presidência da empresa, que assumem papel fundamental no processo de planejamento estratégico e orçamentário.

Ressalte-se que uma limitação presente neste estudo é a possibilidade de viés na interpretação das respostas, tendo em vista que este estudo está associado ao uso de entrevistas. Cabe mencionar ainda que as respostas obtidas dos entrevistados foram livres, não cabendo nenhum interesse pessoal por parte dos autores. 


\section{REFERÊNCIAS}

ACKOFF, Russell Lincoln. Planejamento empresarial. LTC, 1976.

ANTHONY, Robert N.; GOVINDARAJAN, Vijay. Management control systems. 1998.

BEUREN, Ilse Maria; ARI VERHAGEM, José. Remuneração variável incentiva a criação de folga orçamentária? Revista Pensamento Contemporâneo em Administração, v. 9, n. 4, 2015.

BRUNS, William J.; WATERHOUSE, John H. Budgetary control and organization structure. Journal of accounting research, p. $177-203,1975$

COSTA, Alexandre Marino; DE OLIVEIRA MORITZ, Gilberto; MACHADO, Filipe Menezes Vasconcellos. Contribuições do Orçamento Base Zero (OBZ) no planejamento e controle de resultados em organizações empresariais. Revista Contemporânea de Contabilidade, v. 4, n. 8, p. 85-98, 2007.

COVALESKI, Mark et al. Budgeting research: three theoretical perspectives and criteria for selective integration. Handbooks of management accounting research, v. 2, p. 587-624, 2006.

CHRISTENSEN, David; TEMPLIN, Carl. An analysis of management reserve budget on defense acquisition contracts. Acquisition Review Quarterly, v. 7, n. 3, p. 191-207, 2000.

DILLON, Robin L.; PATÉ-CORNELL, Marie-Elisabeth; GUIKEMA, Seth D. Optimal use of budget reserves to minimize technical and management failure risks during complex project development. IEEE Transactions on Engineering Management, v. 52, n. 3, p. 382-395, 2005.

DUAN, Wei. Research on the Budgetary Slack Behavior to the Construction Machinery and Equipment Manufacturing Enterprise in China. In: Advanced Materials Research. Trans Tech Publications, p. 1504-1508, 2014.

DUNK, Alan S. Budgetary participation, agreement on evaluation criteria and managerial performance: a research note. Accounting, Organizations and Society, v. 15, n. 3, p. 171-178, 1990.

DUNK, Alan S.; NOURI, Hossein. Antecedents of budgetary slack: A literature review and synthesis. Journal of Accounting Literature, v. 17, p. 72, 1998.

FREZATTI, Fábio. Orçamento Empresarial: Planejamento e Controle Gerencial. $5^{\text {a }}$ Edição revista e atualizada. Editora Atlas SA, 2009.

FREZATTI, Fábio et al. Perfil de planejamento e ciclo de vida organizacional nas empresas brasileiras. Revista de Administração, v. 45, n. 4, p. 383-399, 2010.

FREZATTI, Fábio et al. Processo orçamentário: uma aplicação da análise substantiva com utilização da grounded theory. Organizações \& Sociedade, v. 18, n. 58, p. 445-466, 2011.

FREZATTI, Fábio; BECK, Franciele; DA SILVA, Júlio Orestes. Percepções sobre a criação de reservas orçamentárias em processo orçamentário participativo. Revista de Educação e Pesquisa em Contabilidade (REPeC), v. 7, n. 4, 2013.

HANSEN, Stephen C.; VAN DER STEDE, Wim A. Multiple facets of budgeting: an exploratory analysis. Management accounting research, v. 15 , n. 4, p. 415-439, 2004.

HOBSON, Jessen L.; MELLON, Mark J.; STEVENS, Douglas E. Determinants of moral judgments regarding budgetary slack: An experimental examination of pay scheme and personal values. Behavioral Research in Accounting, v. 23, n. 1, p. 87-107, 2011.

HUANG, Cheng-Li; CHEN, Mien-Ling. The effect of attitudes towards the budgetary process on attitudes towards budgetary slack and behaviors to create budgetary slack. Social Behavior and Personality: an international journal, v. 37, n. 5, p. 661-671, 2009.

JENSEN, Michael C.; MECKLING, William H. Theory of the firm: Managerial behavior, agency costs and ownership structure. Journal of financial economics, v. 3, n. 4, p. 305-360, 1976.

LEAVINS, John R.; OMER, Khursheed; VILUTIS, Arv. A comparative study of alternative indicators of budgetary slack. Managerial Finance, v. 21, n. 3, p. 52-67, 1995.

LIESSEM, Thomas et al. Budgetary slack under budget-based incentive schemes-the behavioral impact of social preferences, organizational justice, and moral disengagement. Journal of Management Control, v. 26, n. 1, p. 81-94, 2015.

MARTINS, G. D. A.; THEÓPHILO, Carlos Renato. Metodologia da investigação científica para ciências sociais aplicadas. São Paulo: Atlas, v. 3, p. 104-119, 2016

MINTZBERG, Henry; AHLSTRAND, Bruce; LAMPEL, Joseph. Safári da estratégia. Bookman Editora, 2009.

MERCHANT, Kenneth A. Budgeting and the propensity to create budgetary slack. Accounting, Organizations and Society, v. 10, n. 2, p. 201-210, 1985.

MUCCI, Daniel Magalhães; FREZATTI, Fabio; DIENG, Mamadou. As múltiplas funções do orçamento empresarial. RAC-Revista de Administração Contemporânea, v. 20, n. 3, p. 283-304, 2016

SANTOS, Vanderlei et al. Folga Orçamentária: Características das Publicações em Periódicos Internacionais. Contabilidade Vista \& Revista, v. 27, n. 1, 2016. 
WELSCH, Glenn A. Orçamento empresarial: planejamento e controle de lucro. Atlas, 2010.

YOUNG, S. Mark. Participative budgeting: The effects of risk aversion and asymmetric information on budgetary slack. Journal of accounting research, p. 829-842, 1985.

YUEN, Desmond CY. Goal characteristics, communication and reward systems, and managerial propensity to create budgetary slack. Managerial Auditing Journal, v. 19, n. 4, p. 517-532, 2004. 